\title{
Edición diplomática y análisis paleográfico de cuatro manuscritos redactados en Río Grande del Sur, Brasil, entre finales del siglo XIX y el inicio del siglo XX
}

\section{(Diplomatic edition and paleographic analysis of four manuscripts written in Great Southern River, Brazil, between the end of the 19th century and the beginning of the 20th century)}

\author{
TATIANA KELLER/DARIO T. DE ALMEIDA FILHO \\ tatianakeller.ufsm@gmail.com/dt-af@hotmail.com \\ Universidade Federal de Santa Maria (UFSM)
}

Fecha de recepción: 11 de agosto de 2017

Fecha de aceptación: 30 de septiembre de 2017

Resumen: Este artículo presenta ediciones diplomáticas de cuatro manuscritos redactados en Río Grande del Sur, Brasil, entre finales del siglo XIX y principios del siglo $\mathrm{XX}$, así como un análisis paleográfico de los respectivos documentos. En este análisis, observamos aspectos estrictamente ortográficos divergentes en relación con la norma actualmente vigente en la lengua portuguesa, atendiendo a cuatro grandes categorías, con las respectivas subcategorías: sistema vocálico (sustituciones vocálicas, hiato, uso de y); sistema consonántico (grupos consonánticos impropios, consonantes dobles, uso de $\mathrm{h}$, sustituciones de consonantes); diacríticos (acento agudo, acento circunflejo, acento grave, tilde) y separación lexical (hiposegmentación). Resaltamos, de este análisis, los vestigios latinos aún presentes en tales documentos, evidenciando la relación indisociable entre la comprensión de la lengua y el recorrido histórico por ella realizado. Se trata de un material de interés especial para el filólogo, aunque también puede resultar de interés para otros lingüistas como fonólogos y sociolingüistas.

Palabras clave: Filología. Ediciones. Paleografía. Ortografía. Manuscritos.

Abstract: This article presents diplomatic editions of four manuscripts written in Great Southern River, Brazil, between the end of the 19th century and the beginning of the 20th century, as well as a paleographic analysis of the respective documents. In this analysis, we observed strictly orthographic 


\section{TATIANA KELLER/DARIO T. DE AlmEIDA FiLHO}

divergent aspects in relation to the Portuguese current norm, considering four major categories, with the respective subcategories: vowel system (vowel substitutions, hiatus and use of y); consonantal system (improper consonant clusters, double consonants, use of h, consonantal substitutions); diacritics (acute accent, circumflex accent, severe accent, til) and vocabulary separation (hyposogmentation). We point out, from this analysis, to the Latin remnants still present in these documents, evidencing the inextricable relationship between the understanding of the language and the historical route it has traveled. Material of special interest to the philologist, we also believe that it may interest other linguists, such as phonologists and sociolinguists.

Keywords: Philology. Editions. Paleography. Orthography. Manuscripts.

\section{Introdução}

Neste artigo, apresenta-se a edição diplomática de quatro documentos coletados em Santa Maria - RS, bem como sua análise. Do ponto de vista histórico, tal empresa faz-se válida, pois, constituindo-se de documentos de arquivo, contendo fontes primárias sobre dado período, podem elas contribuir para o processo de "construções históricas" do município a que se referem (Merlo; Konrad, 2015: 27). Do ponto de vista linguístico, por sua vez, a importância da referida análise paleográfica é vista no reforço, ou mesmo no acréscimo, de dados relativamente à língua portuguesa escrita no Brasil entre o final do século XIX e o início do século XX. Embora nossa análise restrinja-se a domínio estritamente ortográfico, a própria edição dos textos permite que análises outras sejam eventualmente realizadas.

A seguir, tecemos uma breve consideração acerca dos propósitos definição, utilidade - da edição de um texto; também apresentamos tipos possíveis de edição, sobretudo aquelas baseadas na forma de estabelecimento do texto, com suas respectivas características, virtudes e defeitos; mais a frente, indicamos os princípios norteadores gerais para a realização de nossas edições, mormente a diplomática, além de aspectos paleográficos que serão observados posteriormente; por fim, trazemos à lume a edição diplomática dos manuscritos, bem como sua análise paleográfica.

\section{Fundamentação teórica}

De acordo com Segismundo Spina, "editar um texto consiste em reproduzilo" (1977: 77). A partir dessa definição, podemos afirmar que a função primordial de uma edição é, por meio da reprodução de um texto, torná-lo acessível a um público mais abrangente; seja ao especialista, preocupado com 
Edición diplomática y análisis paleográfico de cuatro manuscritos redactados...

questões referentes ao texto original tal como ele foi redigido, seja ao público geral, isto é, aquele que não possui acesso ao acervo de bibliotecas, arquivos etc., assim como também desconhece noções de filologia que permitam a leitura de textos antigos. Uma função correlata a essa, acrescentamos, reside na preservação do original, uma vez que, feita sua edição, não há mais a necessidade de recorrer a ele com tanta frequência, conservando sua integridade - função especialmente importante no caso de textos raros, muito antigos e/ou frágeis.

Quanto aos tipos de edição, Cambraia (2005: 87-107) distingue duas "macrocategorias", cujos tipos a elas atrelados são classificados de acordo com o critério adotado para sua execução. A primeira alude aos tipos gerais de edição, os quais citamos, ligeiramente, a seguir. A segunda refere-se aos tipos fundamentais de edição, pormenorizados mais abaixo, haja vista sua relevância para as edições aqui realizadas.

As edições concernentes aos tipos gerais podem ser baseadas: no material (acrescentando-se aí duas subcategorias; uma em relação à dimensão do livro e a outra à qualidade do suporte); no sistema de registro (edição impressa ou digital/eletrônica/virtual); na publicação (princeps ou limitada ou extraordinária ou comemorativa); na permissão (autorizada ou clandestina/espúria/fraudulenta/pirata); na integralidade do texto (integral ou abreviada ou expurgada); na reelaboração do texto (revista ou atualizada ou ampliada/aumentada ou modernizada).

Em relação aos tipos fundamentais de edição, que são os que nos interessa, o critério repousa na forma de estabelecimento do texto, cujos princípios são ora elucidados. Ainda segundo Cambraia (2005), existem duas grandes classes de edições assentadas nesse critério: a monotestemunhal (baseada em apenas um testemunho do texto) e a politestemunhal (baseada no cotejo de dois ou de mais testemunhos).

Quanto às edições de caráter monotestemunhal (caso de nossas edições), subdividem-se elas em: fac-similar; diplomática; paleográfica; e interpretativa. As principais diferenças entre elas residem no grau de intervenção do editor sobre o texto no ato mesmo de sua fixação, intervenção essa que está estreitamente intricada ao público almejado pelo editor.

A edição fac-similar baseia-se em um gran zero de mediação, isto é, na pura e na simples reprodução mecânica do texto. Sua principal vantagem é a possibilidade de ser consultada com o mínimo grau possível de intervenção por parte do editor, facilitando o acesso do especialista consulente; por outro lado, justamente por não haver nenhum tipo de apoio por parte do editor, o acesso ao público geral é prejudicado, uma vez que a leitura de uma edição fac-similar 


\section{TATIANA KELLER/DARIO T. DE AlmEIDA FiLHO}

(principalmente, de um texto muito antigo) exige conhecimentos específicos ignorados pelo leitor comum.

A edição diplomática baseia-se em um gran baixo de mediação; implica isso uma transcrição rigidamente conservadora, a fim de preservar todas as características do texto original, mesmo aquelas que já não se verificam na língua. Cambraia (2005: 93) cita como exemplos dessas características "sinais abreviativos, sinais de pontuação, paragrafação, transliteração, separação vocabular etc.”. A principal vantagem desse tipo de edição é a facilitação da leitura, dado que, consultada a edição diplomática, é desnecessário recorrer ao original, que, muitas vezes, em especial manuscritos, oferece dificuldades em relação à grafia do escrevente. Entretanto, precisamente por se propor à conservação das características peculiares ao original, torna-se uma edição voltada para especialistas, munidos de conhecimento técnico para decodificar certas formas que, mesmo que facilitadas em relação à fac-similar, ainda assim se constituem como um obstáculo para o leitor comum. Além disso, deve-se lembrar de que, apesar do grau baixo de mediação por parte do editor, todas as operações efetuadas já implicam sua leitura, que, eventualmente, poderia ser considerada errônea por outro.

O terceiro tipo de edição, que envolve um gran médio de mediação, é a paleográfica (ou, ainda, semidiplomática, paradiplomática ou diplomáticointerpretativa). Em relação à diplomática, o editor atua a fim de facilitar ainda mais a leitura do documento, visando, desse modo, a ampliar seu público leitor, mas, também, a corrigir lapsos óbvios cometidos pelo escrevente (apesar de sempre sinalizar tal correção em nota explicativa). Suas vantagens e desvantagens estão relacionadas a essas operações: ao aumentar seu potencial público leitor, o editor pode comprometer certas características particulares do texto editado ao corrigir, por exemplo, o que considerou certo lapso do escrivão, desenvolver um sinal abreviativo equivocadamente etc.

O último tipo é a edição interpretativa, que implica o gran máximo de mediação admissivel. Aqui, os procedimentos adotados visam à acessibilidade, ainda maior, do público ao texto editado. Algumas das operações efetuadas incluem uniformização gráfica (e essencialmente gráfica, excluídas, portanto, variantes fonológicas, morfológicas, sintáticas e lexicais) e, segundo Cambraia (2005: 97), "intervenções que aproximem o texto do que teria sido sua forma genuína", o que diferencia tal edição da paleográfica; pois, o processo de intervenção é ainda mais acentuado, envolvendo mesmo um ato de interpretação por parte do editor. Quanto às vantagens e desvantagens, são semelhantes às da edição paleográfica, porém em um grau mais evidente, haja vista o risco que corre o editor na maior intervenção do texto. 
Edición diplomática y análisis paleográfico de cuatro manuscritos redactados...

As edições politestemunhais, por sua vez, possuem dois tipos, comumente empregadas em textos literários: a edição crítica e a edição genética.

A edição crítica tem como objetivo maior fixar a versão mais próxima daquela a que seu autor teria desejado por meio do cotejo entre testemunhos, geralmente apógrafos (cópia do original), do mesmo texto.

A edição genética realiza o mesmo procedimento da edição crítica; a diferença fundamenta-se no tipo de testemunho confrontado: enquanto a edição crítica utiliza testemunhos apógrafos, a edição genética serve-se de autógrafos (originais). Além de fixar a versão final almejada pelo autor do texto, a edição genética também traça todo o processo de desenvolvimento do texto desde sua primeira versão até a versão final, possibilitando uma leitura mais abrangente do processo criativo de seu autor.

\section{Metodologia}

Tomamos como corpus quatro manuscritos redigidos e alocados no estado Rio Grande do Sul (Brasil). O primeiro manuscrito (A) foi redigido, em 1910, por um delegado local, em Santa Maria, e trata-se de um relatório investigativo enviado ao juiz distrital da sede da comarca da cidade. O segundo (B) refere-se à nomeação interina de um cidadão a reger aula pública na seção Arroio Lobato, localizada na cidade de Silveira Martins. Escrita, em 1896, por um inspetor escolar, é remetida ao presidente da Intendência Municipal de Santa Maria. O terceiro (C), por sua vez, escrito em Carazinho, em 1902, trata-se de uma escritura particular relativa à venda de uma chácara. O manuscrito (D), por fim, registra a dispensa, em 1911, de um soldado dos quadros de um esquadrão do exército. Não há referência quanto ao local de escritura de tal manuscrito, apesar de ele ter sido coletado em Santa Maria.

A coleta dos dados deu-se, em Santa Maria, através da captação fotográfica dos referidos manuscritos em três locais: no Arquivo Histórico Municipal de Santa Maria, onde estão alocados A e B; na Casa de Memória Edmundo Cardoso, localização de C; e no Centro Histórico Coronel Pilar, onde foi coletado D.

No tocante às normas empregadas na edição dos manuscritos, adotamos as propostas de Cambraia (2005). Segundo o autor, o mundo lusófono, pela falta de tradição filológica, carece de diversidade normativa no processo de edição de textos antigos. A fim de oferecer uma alternativa, Cambraia sugere um conjunto básico de normas a serem aplicadas em edições diplomáticas, paleográficas e interpretativas. As edições fac-similares, por envolverem dificuldades de ordens diversas (por exemplo, tecnológica), e as genéticas, por serem ainda por demasiado recentes, não são abordadas pelo autor. 


\section{TATIANA KELLER/DARIO T. DE AlmEIDA FiLHO}

Por ser a edição diplomática a aqui realizada, mencionamos apenas as normas por Cambraia propostas para ela:

a) Caracteres alfabéticos: transcrever como caracteres romanos redondos, reproduzindo-se as diferenças de módulo e dos alógrafos contextuais como no modelo. Quando houver mais de um tipo de caractere no modelo (como, p. ex., capitulares), diferenciá-los na transcrição.

b) Sinais abreviativos: transcrever fielmente.

c) Diacríticos: transcrever fielmente.

d) Sinais de pontuação: transcrever fielmente.

e) Caracteres de leitura duvidosa: transcrever entre parênteses redondos simples 0 .

f) Caracteres de leitura impossivel: transcrever como pontos dentro de colchetes precedidos pela cruz † (o número de pontos é o de caracteres não legíveis).

g) Caracteres riscados: transcrever com tachado.

h) Caracteres apagados, modificados, nas entrelinhas ou nas margens: informar em nota.

i) Separação vocabular (intra- e interlinear): reproduzir fielmente.

j) Paragrafação: reproduzir fielmente.

1) Inserções conjecturais: não realizar nenhuma.

m) Supressões conjecturais: não realizar nenhuma.

n) Mudança de fólio, face e coluna: informar na margem de cabeça, em itálico e entre colchetes simples: [].

o) Mudança de punbo: informar em nota.

p) Mudanças de tinta: informar em nota.

q) Qualquer outra particularidade: informar em nota.

r) Numeração de linha: inserir na margem externa, contando de 5 em 5, de forma contínua em todo o texto (2005: 128-129)

\section{Apresentação das edições}

4.1. Manuscrito $A$

4.1.1. Edição diplomática

\begin{tabular}{|l|l|}
\hline LOCAL & Santa Mariao, Rio Grande do Sul, Brasil \\
\hline DATA & 04 de março de 1910 \\
\hline COTA & Arquivo Histórico Municipal de Santa Maria \\
\hline TIPO DE DOCUMENTO & Relatório investigativo \\
\hline
\end{tabular}

Estado do Rio Grande do Sul

Delegacia de Policia em Santa Maria, 
Edición diplomática y análisis paleográfico de cuatro manuscritos redactados...

4 de Março de 1910

Ao Cidadão Juiz Districtal da Sede da Comarca de S. Maria

Tendo terminado as investigações policiaes sobre o crime de infanticídio de que saõ autores Josephina Cortulo e sua mãe Vitoria Cortulo, para ás vossas mãos o competente relatorio afim de ser juntado dos autos que em tempo já vos remetti.

Saude e fraternidade

João [Belém]

Delegado

4.2. Manuscrito B

4.2.1. Edição diplomática

\begin{tabular}{|l|l|}
\hline LOCAL & Silveira Martins, Rio Grande do Sul, Brasil \\
\hline DATA & 10 de julho de 1896 \\
\hline COTA & Arquivo Histórico de Santa Maria \\
\hline TIPO DE DOCUMENTO & Nomeação de professor interino \\
\hline
\end{tabular}

Silveira Martins, 10 de Julho de 1894

Cidadão Presidente da Intendencia Municipal de S. Maria:

De acordo com o \$. 10, artigo 19, do Regulamento da Instrucção Publica, communico-vos que o cidadão Jose da Silva Brasil, nomeado para interinamente reger a aula publica da secção "Arroio Lobato", 
TATIANA KELLER/DARIO T. DE AlmeIDA FiLHO

10

desta ex-Colonia, entrou em exercicio do [seo] cargo no dia 27 de Junho $\mathrm{p}^{\circ}$ passado, Saude e Fraternidade.

O Inspector Escolar:

Olyntho [Couto]

4.3. Manuscrito $C$

4.3.1. Edicão diplomática

\begin{tabular}{|l|l|}
\hline LOCAL & Carazinho, Rio Grande do Sul, Brasil \\
\hline DATA & 10 de maio de 1902 \\
\hline COTA & Casa de Memória Edmundo Cardoso \\
\hline TIPO DE DOCUMENTO & Escritura de venda \\
\hline
\end{tabular}

Escriptura particular de venda da parte de uma chacara, faz Manoel Machado dos Santos; a Maria Candida Silva, como abaixo se declara

5

10

15

20

110
Eu abaixo assignado Manoel Machado dos Santos, declaro que entre os mais bens que possuo livre e desembargados de epotheca e Onus, e bem asssim uma parte em uma chacara que herdei por fallecimento de meu Pay, Jose Maria Machado sitta nos soburbios da cidade de Santa Maria da Boca do Monte. Nesta data de minha livre e expontan $\sim$ ea vontade vendi como de fato vendido tenho arreferida parte na chaca-

ra Sñra Maria Candida da Silva, péla a quantia entre nós justada de cento e vinte milreis [†.. pamente] (120.000) que recebi da compradora no ato de firmar apresente escriptura particular que vallerá como se publica fosse. Podendo acompradora to-

Alfinge 29 (2017), 103-124 
Edición diplomática y análisis paleográfico de cuatro manuscritos redactados...

mar posse edominio da referida par-

te na chacara, desde já como sua

que é e ficará sendo de hoje para

sempre; do que lhe dou plena e ge-

ral quitação. Obrigando-me fazer

Escriptura particular de venda da

30 parte de uma chacara, faz Mano-

el Machado dos Santos; a Maria Candi-

da Silva, como abaixo se declara

Eu abaixo assignado Manoel Machado dos Santos, declaro que entre os mais bens que possuo livre e desembargados de epotheca e Onus, e bem asssim uma parte em uma chacara que herdei por fallecimento de meu Pay, Jose Maria Machado sitta nos soburbios da cidade de Santa Maria da Boca do Monte. Nesta data de minha livre e expontan $\sim$ ea vontade vendi como de fato vendido tenho arreferida parte na chacara Sñra Maria Candida da Silva, péla a quantia entre nós justada de cento e vinte milreis [†.. pamente] (120.000) que recebi da compradora no ato de firmar apresente escriptura particular que vallerá como se publica fosse. Podendo acompradora tomar posse edominio da referida parte na chacara, desde já como sua que é e ficará sendo de hoje para sempre; do que lhe dou plena e geral quitação. Obrigando-me fazer ${ }^{1}$ duvida havia o por haver; e élla obrigada ao pagamento da competente siza. Em virtude do que acima

1 A partir desse ponto, o texto não segue a sequência lógica do dito anteriormente. Aparentemente, a linha final da primeira parte da fotografia que permitiu a edição fac-similar não foi capturada. 
60 fica dito mandei passar apresente que firmo a minha enteira satisfacção, com as testemunhas abaixo.

Carazinho, 10 de Maio de 1902

Manoel Machado dos Santos

Ismael Gomes de [†.il†...y]

Testemunhas.

Manoel Pereira dos Santos

4.4. Manuscrito D

4.4.1. Edição diplomática

\begin{tabular}{|l|l|}
\hline LOCAL & Santa maria, Rio Grande do Sul \\
\hline DATA & Fevereiro de 1911 \\
\hline COTA & Centro Histórico Coronel Pilar \\
\hline TIPO DE DOCUMENTO & Registro de dispensa de soldado \\
\hline
\end{tabular}

\begin{tabular}{|c|c|c|}
\hline Nome e filiação & Signaes & Sahida \\
\hline Ismael Ribeiro & Cor indiatica & \multirow{2}{*}{$\begin{array}{c}\text { Em 4 de Feve- } \\
\text { reiro de 1911 } \\
\text { por conclusão de } \\
\text { tempo. }\end{array}$} \\
\cline { 1 - 2 } Filho de Balduino Alves & Cabellos pretos & Olhos pardos \\
\hline Nasceu em 1886 & Officio & Estado solteiro \\
\cline { 1 - 2 } Natural deste Estado & \multicolumn{2}{|c|}{ Esquadrão $n^{\circ}$ 32. Soldado } \\
\hline
\end{tabular}

\section{OBSERVAÇÕES}

(vem da folha $\mathrm{n}^{\mathrm{o}} 178$ do livro $\mathrm{n}^{\circ}$ )

Em 1911: Janeiro: Pelo artigo sexto dos aponta mentos do Commando da Brigada de $[+\ldots]$ foi publico

5 ter regressado para São Borja. Fevereiro: Pela ordem do dia regimental numero dois mil sessenta de quatro, foi excluido do estado effectivo do regimento e deste esquadrão com baixa por con clusão de tempo.

\section{Comentários paleográficos}


Edición diplomática y análisis paleográfico de cuatro manuscritos redactados...

Quanto à análise paleográfica dos manuscritos, convém, antes, definir o domínio da Paleografia. Segundo Spina (1977: 18), a Paleografia é o "estudo das antigas escritas e evolução dos tipos caligráficos em documentos, isto é, em material perecível (papiro, pergaminho, papel)". Para o presente estudo, consideramos quatro grandes categorias, com as respectivas subcategorias: sistema vocálico (substituições vocálicas, hiato, uso do y); sistema consonantal (encontros consonantais impróprios, consoantes duplas, uso do h, substituições consonantais); diacríticos (acento agudo, acento circunflexo, acento grave, til) e separação vocabular (hipossegmentação) ${ }^{2}$.

\subsection{Sistema vocálico}

\subsubsection{Substituição vocálica}

As substituições vocálicas foram verificadas em três dos quatro documentos analisados, as quais estão ilustradas no Quadro 1. Observamos a substituição de $i$ por $e$ em três desses casos, ainda que em contextos fonéticos distintos: em A, policiaes $>$ policiais; e em C, epotheca $>$ hipoteca; enteira $>$ inteira. Além disso, constatamos, em $\mathrm{B}$ e em $\mathrm{C}$, a substituição de $u$ por 0 , ainda que também em contextos fonéticos distintos: em B, seo > seu; em C, soburbios > subúrbios.

\begin{tabular}{|c|c|c|c|}
\hline MANUSCRITO & VOCÁBULO & FAC-SÍMILE & $\begin{array}{c}\text { SUBSTITUIÇÃ } \\
\text { O }\end{array}$ \\
\hline A & policiaes & utheriaes & $i$ por $e$ \\
\hline B & seo & $P 2=$ & $u$ por $o$ \\
\hline $\mathrm{C}$ & epotheca & efratheca & $i$ por $e^{3}$ \\
\hline $\mathrm{C}$ & soburbios & Dobunbio & $u$ por $o$ \\
\hline
\end{tabular}

${ }^{2}$ Existem, naturalmente, outras subcategorias associadas às mencionadas; aqui, referimos, porém, apenas as subcategorias efetivamente encontradas nos manuscritos.

3 Além disso, há uma omissão de $b$ inicial e acréscimo de $h$ medial, casos detalhados em 5.2.3. 
TATIANA KELLER/DARIO T. DE AlmeIDA FiLHO

\begin{tabular}{|c|c|c|c|}
\hline $\mathrm{C}$ & enteira & erzutecesce & \multirow{2}{*}{$i$ por $e$} \\
\hline $\mathrm{D}$ & signaes & Signaes & \multirow{2}{*}{$i$ por $e$} \\
\hline
\end{tabular}

Quadro 1: substituições vocálicas

\subsubsection{Hiato}

Constatamos apenas uma ocorrência, a qual pode ser observada no Quadro 2. No documento D, sabida > saída. Edwin B. Williams (2001: 35) lembra que era corrente, até o Acordo Ortográfico de 1911, que se utilizasse o $h$ como marcador de hiato entre duas vogais diferentes ou de qualidade diferente. Como exemplo, o autor fornece letreiros justamente com a palavra saida/sabida para distinguir entre teatros novos e antigos de Lisboa. Salientamos que essa é uma característica do denominado por Williams de período fonético, coincidente com o período do português arcaico.

\begin{tabular}{|c|c|c|c|}
\hline MANUSCRITO & VOCÁBULO & FAC-SÍMILE & OCORRÊNCIA \\
\hline D & sahida & Sahida & $b i$ \\
\hline
\end{tabular}

Quadro 2: ocorrência de hiato

\subsubsection{Uso doy}

Encontramos apenas um caso: a permuta de $i$ por $y$ no final do vocábulo pay $>$ pai. Sobre o y, esse seria, segundo Williams (2001), um caso típico de confusão de grafias, a qual também incluía o $j$. Sobre isso, esclarece-nos Said Ali (2001) que o emprego do $y$ era muito usual em ditongos, fazendo o $y$ as vezes de semivogal. Como se pode notar no recorte fac-similar abaixo, há um sinal que se assemelha a um acento agudo, mas que também pode ser apenas algum sinal outro sobre o papel. Por não fazer sentido fonológico, acreditamos tratarse do segundo caso.

\begin{tabular}{|c|c|c|c|}
\hline MANUSCRITO & VOCÁBULO & FAC-SÍMILE & SUBSTITUIÇÃO \\
\hline C & pay & & \\
& & &
\end{tabular}

Quadro 3: ocorrência de y em lugar de i 
Edición diplomática y análisis paleográfico de cuatro manuscritos redactados...

\subsection{Sistema consonantal}

\subsubsection{Encontro consonantal impróprio}

Dentre todas as dissonâncias observadas com a ortografia atual da língua portuguesa, foi um dos casos mais comuns encontrados; em sua maioria, casos de $c$ hoje mudos. Tais encontros estão ilustrados no Quadro 4.

$\mathrm{O} p$ do vocábulo escriptura, encontrado em $\mathrm{C}$ é o denominado por Williams (2001: 38) de "p ortográfico intruso" comumente acrescido às derivações do verbo escrever, possivelmente em virtude de formas latinas como scripsi e scriptus. O caso dos vocábulos assignado $>$ assinado (C) e signaes $>$ sinais (D) justifica-se, conforme Williams (2001: 94), pela perda do $g$ de gn em vocábulos semieruditos, enquanto em outros casos tornou-se o $\mathrm{nh}$, como, por exemplo, em pugnum $>$ punho. Vale ressaltar que alguns vocábulos de via semierudita tiveram, no período etimológico, o $g$ restaurado gráfica e foneticamente: digno, benigno, maligno. Caso mesmo de signo, cuja raiz etimológica é compartilhada com sinal (do latim signum, i).

Os demais encontros consonantais ( $c t$ e $c c)$ ), também são herdados do latim, língua na qual as consoantes eram pronunciadas: districtal (do latim districtus, us); instrucção (instructio, onis); secção (sectio, onis); inspector (inspector, oris) satisfacção (satisfactio, onis); effectivo (effectivus, a, um). Alguns desses casos foram mantidos pelo Acordo Ortográfico de 1945 (por exemplo, secção e inspector), enquanto outros foram eliminados (casos de districtal > distrital; satisfacção > satisfação) ${ }^{4}$. O Acordo Ortográfico de 1990 eliminou tais sequências consonantais em casos cuja pronúncia era invariavelmente muda ${ }^{5}$.

Além disso, destacamos o caso do vocábulo sastisfacção $>$ satisfação. O acréscimo do $s$ em contexto VC parece ser um possível lapso do redator.

\begin{tabular}{|c|c|c|c|}
\hline MANUSCRITO & VOCÁBULO & FAC-SÍMILE & ENCONTRO \\
\hline \multirow{2}{*}{$\mathrm{A}$} & districtal & Dissec & ct \\
& & & \\
\hline
\end{tabular}

\footnotetext{
4 Cf. Documento n. ${ }^{\circ}$ 2: Bases Analíticas do Acordo Ortográfico de 1945. Disponível em: http://www.portaldalinguaportuguesa.org/acordo.php?action=acordo\&id=8-6\&version=1945. [Acesso em: 25 de setembro de 2017]

5 Cf. Acordo Ortográfico da Língua Portuguesa de 1990. Disponível em: http://www.portaldalinguaportuguesa.org/acordo.php?action=acordo\&version=1990. [Acesso em: 25 de setembro de 2017]
} 
TATIANA KELLER/DARIO T. DE AlmeIDA FiLHO

\begin{tabular}{|c|c|c|c|}
\hline B & instrucção & 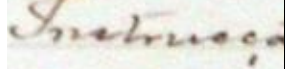 & $c c$ \\
\hline B & secção & enes, & $c c$ \\
\hline B & inspector & & $c t$ \\
\hline C & assignado & ossignectolo & $g n$ \\
\hline C & escriptura & niptassa & $p t$ \\
\hline C & sastisfacção & & $s f, c c$ \\
\hline $\mathrm{D}$ & signaes & Signaes & $g n$ \\
\hline $\mathrm{D}$ & effectivo & elceabito & $c t$ \\
\hline
\end{tabular}

Quadro 4: Encontros consonantais impróprios

\subsubsection{Consoante dupla}

Outro dos aspectos paleográficos mais recorrentes verificados nos textos analisados; de acordo com o Williams (2001), a consoante dupla seria uma reminiscência do latim, língua em que exercia uma função fonética. É importante notar que todos os casos encontrados são de consoantes duplas em posição intervocálica e, portanto, sem função fonética; a consideração faz-se pertinente, pois, para Williams, casos de consoantes duplas em posições não intervocálicas teriam, possivelmente, fins fonéticos. As ocorrências de consoantes duplas figuram no Quadro 5.

Said Ali (2001: 40), por outro lado, afirma não haver fundamento etimológico para o emprego de $l l$ (fallecimento $>$ falecimento; vallerá $>$ valerá) e ff (effectivo > efetivo) em contexto intervocálico; de acordo com o autor, "as obras 
Edición diplomática y análisis paleográfico de cuatro manuscritos redactados...

latinas que constituíam a principal leitura desses tempos [do português arcaico], e donde se tiravam alguns dos referidos vocábulos diretamente, deviam antes induzir a fazer uso do l simples". A hipótese levantada pelo autor (2001: 40) seria uma possível ênfase das vogais juntas às consoantes geminadas com fins de sinalizar "intonação [sic] ou icto forte, mas muito rápido".

\begin{tabular}{|c|c|c|c|}
\hline MANUSCRITO & VOCÁBULO & FAC-SÍMILE & $\begin{array}{c}\text { CONSOAN } \\
\text { TES }\end{array}$ \\
\hline A & remetti & - fli & tt \\
\hline B & communico & $\frac{\mathrm{com}-1}{m \mathrm{man}}$ & $\mathrm{mm}$ \\
\hline $\mathrm{C}$ & fallecimento & fallocünzenzto & $l l$ \\
\hline $\mathrm{C}$ & sita & & $t$ \\
\hline $\mathrm{C}$ & vallerá & vallesál & $l l$ \\
\hline $\mathrm{C}$ & élla & & ll \\
\hline $\mathrm{D}$ & effectivo & aceiro & $f f$ \\
\hline $\mathrm{D}$ & officio & Officio & $f f$ \\
\hline $\mathrm{D}$ & commando & 60 . & $\mathrm{mm}$ \\
\hline
\end{tabular}

Quadro 5: consoantes duplas

\subsubsection{Uso do h}

Esse poderia ser um caso de resquício do denominado por Williams (2001) de período etimológico, iniciado no Renascimento e estendido até ao século XX. Uma das características desse período foi a retomada de vocábulos de origem latina e grega, embora incongruentes quanto à pronúncia; daí a profusão 


\section{TATIANA KELLER/DARIO T. DE AlmEIDA FiLHO}

de palavras com $c h, p h, r h, t h$ (nosso caso) e $y$. Curioso é o fato de o redator do manuscrito $\mathrm{C}$ omitir, em epotheca (como se vê no Quadro 6), o $b$ no início do vocábulo e acrescentá-lo em um contexto $C V$, uma vez que o $h$ não desempenha papel fonético algum em ambos os casos.

Uma explicação possível para a omissão do $b$ inicial é justamente pelo fato de ele não exercer função fonológica. Segundo o Acordo Ortográfico de 1911, o $b$ inicial deve ser preservado somente quando a etimologia assim o justifique ${ }^{6}$. $\mathrm{O}$ mesmo Acordo Ortográfico determina que o $h \mathrm{em}$ posição medial deve ser eliminado de todas as palavras (exceto vocábulos com $c h$, th e $n h$ ), adotando, desse modo, um critério fonético para tal caso. De fato, conforme atesta Barbosa (2009), a etimologização (ou, como no referido documento, pseudoetimologização) era um recurso frequentemente utilizado por redatores do século XIX para mostrarem-se mais letrados.

Sendo a palavra hipoteca de origem grega (bupotheke, es), o redator compõe uma solução curiosa para o vocábulo, invertendo o que posteriormente seria estabelecido pelo referido Acordo: no caso do $h$ inicial, utiliza o critério fonético para omiti-lo, admitindo, entretanto, o critério etimológico no emprego do $h$ medial.

A respeito desse vocábulo, cabe, ainda, uma consideração acerca do processo de hipercorreção, diretamente ligado à pseudo-etimologização. A ausência de função fonética do $b$ inicial pode ter levado o escrevente a considerar que sua inclusão conferiria maior lustro à sua escrita. Madureira Feijó (1734) inclui bypothéca como vocábulo passível de ser escrito incorretamente, sem o $b$ inicial, provavelmente em virtude da ausência de função fonética. Correspondência similar, embora não perfeita é apontada por Madureira Feijó (17344) em relação à palavra iludir, grafada erroneamente em seu tempo como enludir, indicando a som vacilante entre $i$ e $e$.

\begin{tabular}{|c|c|c|c|}
\hline MANUSCRITO & VOCÁBULO & FAC-SÍMILE & OCORRÊNCIA \\
\hline C & epotheca & eyrattecea & th \\
\hline
\end{tabular}

Quadro 6: uso do h

\subsubsection{Substituiçôes consonantais}

Said Ali (2001) informa-nos que até, aproximadamente, meados do século

${ }^{6}$ Cf. Formulário Ortográfico de 1991 quanto à letra $b$ em posições inicial e medial. Disponível em: http://www.portaldalinguaportuguesa.org/?action=acordo\&version=1911. [Acesso em: 07 jul. 2017] 
Edición diplomática y análisis paleográfico de cuatro manuscritos redactados...

XVI a distinção entre $s$ e ₹ era realizada de acordo com a fonética. Contudo, a partir desse período, com a prevalência do critério etimológico (ou mesmo pseudoetimológico) sobre o fonético, passa-se a se confundir a ortografia das palavras. Um exemplo aludido pelo autor é o da edição de 1604, impressa em Coimbra, dos Diálogos, de Amador Arrais. Dentre outros vocábulos, o autor destaca as formas cambiantes utilizadas pelo impressor do verbo fazer e de suas respectivas conjugações: ora emprega a forma consonante com a tradição, ora aplica a inovadora forma faser.

Quanto ao vocábulo expontanea, podemos inferir que o $x$ corresponde a $x$ e a $s$ latinos, o que pode ter confundido o redator do texto. Etimologicamente, tal mudança não encontra fundamento, haja vista que o vocábulo espontâneo deriva do latim tardio spontaneus, a, um, caso que pode evidenciar uma tentativa de erudição malograda por parte do escrevente.

Os casos de substituição consonantal estão listados no Quadro 7.

\begin{tabular}{|c|c|c|c|}
\hline MANUSCRITO & VOCÁBULO & FAC-SÍMILE & CONSOANTE \\
\hline $\mathrm{C}$ & $\mathrm{faz}$ & fos & \multirow{2}{*}{ zpors } \\
\hline $\mathrm{C}$ & espontanea & exponztonz & xpors \\
\hline $\mathrm{C}$ & fazer & fousen & zpors \\
\hline
\end{tabular}

Quadro 7: substituições consonantais

\subsection{Diacríticos ou notacões léxicas}

De acordo com Celso Cunha e Lindley Cintra:

Além das letras do alfabeto, servimo-nos, na língua escrita, de certo número de sinais auxiliares, destinados a indicar a pronúncia exata da palavra. Esses sinais acessórios da escrita [são] chamados [de] NOTAÇÕES LÉXICAS (2013: 78).

Apenas por meio de sucessivos Acordos Ortográficos, iniciados no século XX, é que as grafias fonéticas foram estabilizadas (Williams, 2001). Desse

${ }^{7}$ Notar que, conforme o recorte fac-similar, o til está posto sobre o e. No quadro, evitou-se tal colocação pela impossibilidade de sua representação gráfica. 
modo, é esperado que sejam em relação aos diacríticos dos textos, todos anteriores aos Acordos Ortográficos, que ocorram as maiores divergências relativas à ortografia atual, uma vez que tais notações léxicas estão estreitamente vinculadas à pronúncia dos vocábulos, que, quando não subordinadas a convenções, tornam-se suscetíveis à percepção fonética variável de cada indivíduo.

Neste trabalho, analisamos os diacríticos: acento agudo, acento circunflexo e til.

\subsubsection{Acento agudo}

Encontramos, na maioria dos casos, palavras paroxítonas não acentuadas, embora também algumas proparoxítonas (publica $>$ pública; chacara $>$ chácara; numero $>$ número). Ressaltamos, também, o acento agudo utilizado no lugar do hoje normativo acento grave para denotar crase (em A, ás > às) e mesmo em vocábulos em que hoje já não se utiliza (em $\mathrm{C}$, élla $>$ ela). Observemos as ocorrências no Quadro 8.

\begin{tabular}{|c|c|c|c|}
\hline MANUSCRITO & VOCÁBULO & FAC-SÍMILE & OCORRÊNCIA \\
\hline A & policia & & $i$ \\
\hline A & ás & & àpor ás \\
\hline A & infanticidio & & $i$ \\
\hline A & relatorio & & 0 \\
\hline A & saude & & u \\
\hline B & publica $^{8}$ & $\mathrm{O}_{2}$, bliea & u \\
\hline B & exercicio & expenoso & $i$ \\
\hline
\end{tabular}

${ }^{8}$ Duas ocorrências em B. 
Edición diplomática y análisis paleográfico de cuatro manuscritos redactados...

\begin{tabular}{|c|c|c|c|}
\hline B & saude & elanede & u \\
\hline $\mathrm{C}$ & chacara $^{9}$ & $1 a_{3}$ & $a$ \\
\hline $\mathrm{C}$ & soburbios & Sobunbios & u \\
\hline $\mathrm{C}$ & péla & la & $e$ \\
\hline $\mathrm{C}$ & dominio & edonninviol & $i$ \\
\hline $\mathrm{C}$ & élla & $a$ & $e$ \\
\hline $\mathrm{C}$ & reis & milneis & $e$ \\
\hline $\mathrm{D}$ & indiatica & isuciatec & $a$ \\
\hline $\mathrm{D}$ & numero & $2 \mathrm{c}_{2}$ & u \\
\hline $\mathrm{D}$ & excluido & exceces & $i$ \\
\hline
\end{tabular}

Quadro 8: acento agudo

\subsubsection{Acento circunflexo}

Hoje empregado para indicar o timbre semifechado das vogais tônicas $a, e \mathrm{e}$ $o$, foi encontrado três casos: dois, envolvendo a vogal $o$ e um a vogal $e$, como vemos no Quadro 9.

\begin{tabular}{|c|c|c|c|}
\hline MANUSCRITO & VOCÁBULO & FAC-SÍMILE & OCORRÊNCIA \\
\hline \multirow{2}{*}{ B } & intendencia & semein. & $e$ \\
& & - & \\
\hline
\end{tabular}

${ }^{9}$ Quatro ocorrências em C. 
TATIANA KELLER/DARIO T. DE AlmeIDA FiLHO

\begin{tabular}{|c|c|c|c|}
\hline $\mathrm{B}$ & colonia & 0 & 0 \\
\hline $\mathrm{C}$ & onus & Orases, & 0 \\
\hline
\end{tabular}

Quadro 9: acento circunflexo

\subsubsection{Til}

A função do til é indicar a nasalidade das vogais $a$ e $o$. Foi apenas com o Acordo Ortográfico de 1945 que se normalizou seu emprego: quando nasalizada e sucedida por outra vogal, indica-se a nasalidade da vogal anterior pelo til ${ }^{10}$, o que pode justificar o caso do manuscrito A (saõ > são).

$\mathrm{O}$ caso de expontanea > espontânea pode ser influência da norma supracitada: o fato de ser palavra antecedida por $n$ e sucedida por vogal talvez tenha levado o redator a tomar o $e$ como vogal nasalizada, indicado pelo emprego do til.

Todos esses casos estão no Quadro 10.

\begin{tabular}{|c|c|c|c|}
\hline MANUSCRITO & VOCÁBULO & FAC-SÍMILE & OCORRÊNCIA \\
\hline A & saõ & saó & saõ \\
\hline C & expontanea $^{11}$ & exporztonnd & $e$ \\
\hline
\end{tabular}

Quadro 10: til

\subsection{Separação vocabular indevida \\ 5.4.1. Hipossegmentação}

Dentre os manuscritos analisados, encontramos essa ocorrência apenas no manuscrito C. A hipossegmentação, isto é, a união indevida de palavras entre si, é um processo comum em crianças em fase de aquisição da escrita, ou seja, ainda sem prática apurada; sendo o único manuscrito redigido por particular, é plausível considerar que o escrevente também teria pouca prática de escrita, e, por isso, incorreu em tais equívocos.

Os casos de hipossegmentação estão no Quadro 11.

${ }^{10}$ Cf. Documento n. ${ }^{\circ}$ 2: Bases Analíticas do Acordo Ortográfico de 1945, item 12, 1. . Disponível em: $\quad$ http://www.portaldalinguaportuguesa.org/acordo.php?action=acordo\&id $=8$ 6\&version=1945. [Acesso em: 08 jul. 2017]

${ }^{11}$ Cf. nota 23 . 
Edición diplomática y análisis paleográfico de cuatro manuscritos redactados...

\begin{tabular}{|c|c|c|c|}
\hline MANUSCRITO & VOCÁBULO & FAC-SÍMILE & OCORRÊNCIA \\
\hline $\mathrm{C}$ & arreferida & ansefervida & a referida \\
\hline $\mathrm{C}$ & milreis & milnois & mil reis \\
\hline $\mathrm{C}$ & apresente ${ }^{12}$ & afunesente & a presente \\
\hline C & acompradora & acomiruad & a compradora \\
\hline $\mathrm{C}$ & edominio & edonninuio & e dominio \\
\hline
\end{tabular}

Quadro 11: separação vocabular indevida

\section{Considerações finais}

Além da edição fac-similar e diplomática de quatro documentos, permitindo, assim sua divulgação a fim de fornecer dados para estudos posteriores, sejam históricos, sejam linguísticos, destacamos a análise paleográfica realizada.

Em muitos aspectos, foi possível observar divergências entre o estado ortográfico da língua atual e antes dos Acordos Ortográficos realizados ao longo do século XX (bem evidentes no caso dos diacríticos). Outrossim, também ressaltamos os indícios de mudança da língua portuguesa a partir de sua matriz latina (em especial, nos encontros consonantais), bem como das influências sofridas por ela, ao longo da sua história, ora pela prevalência de critérios etimológicos, ora de critérios fonéticos.

\section{Referências bibliográficas}

BARBOSA, Afranio Gonçalves, "Novos corpora para estudos diafásicos: cartas pessoais e cartas publicadas em jomais do séc. XIX." Em: Veröffentlichungsreibe des Studienbereiches Neue Romania des Instituts fir Romanische Philologie der FU. Berlin, v. ba39, 2009, 197-218.

CAmbraiA, César N., Introdução à Crítica Textual. São Paulo: Martins Fontes, 2005.

Madureira Feijó, João de Moraes, Ortographia ou Arte de Escrever, e Pronunciar com acerto a Lingua Portugueza... Lisboa: Officina de Miguel Rodrigues, 1734.

Merlo, Franciele; KOnRAD, Glaucia, "Documento, História e Memória: a importância da preservação do patrimônio documental para o acesso à

12 Duas ocorrências em C. 
TATIANA KELLER/DARIO T. DE AlmEIDA FILHO

informação". Em: Informação \& Informação, 20, 2015, 26-42.

SAID Ali, Manuel, Gramática Histórica da Lingua Portuguesa. São Paulo: Melhoramentos, 2001.

SPINA, Segismundo, Introdução à Edótica. São Paulo: Cultrix, 1977.

Williams, Edwin B., Do Latim ao Português, 7. ed. Rio de Janeiro: Tempo Brasileiro, 2001. 